\title{
The Establishment of a Financial Crisis Early Warning System for Domestic Listed Companies Based on Two Neural Network Models in the Context of COVID-19
}

\author{
Feixiong-Ma, ${ }^{1}$ Yingying-Zhou $\mathbb{D},{ }^{1}$ Xiaoyan-Mo, ${ }^{2}$ and Yiwei-Xia ${ }^{1}$ \\ ${ }^{1}$ School of Business, Guangdong University of Foreign Studies, Guangzhou 510006, China \\ ${ }^{2}$ School of English and Education, Guangdong University of Foreign Studies, Guangzhou 510006, China \\ Correspondence should be addressed to Yingying-Zhou; 20170401730@gdufs.edu.cn
}

Received 15 May 2020; Accepted 15 July 2020; Published 24 August 2020

Academic Editor: Kalyana C. Veluvolu

Copyright (c) 2020 Feixiong-Ma et al. This is an open access article distributed under the Creative Commons Attribution License, which permits unrestricted use, distribution, and reproduction in any medium, provided the original work is properly cited.

In the context of COVID-19, many companies have been affected by the financial crisis. In order to carry out a comparative study on the accuracy of the company's financial crisis early warning method, this study used RPROP artificial neural network and support vector machine, with 162 listed companies' two-year panel financial indicator data as a model sample, and the test sample established a financial crisis early warning model. The theory of comprehensive evaluation combining two kinds of neural network methods is put forward innovatively. The predicted results can strengthen the supervision of the listed companies with risks by themselves and others and have important economic and social significance to ensure the stable operation of the listed companies, the securities market, and the national economy.

\section{Introduction}

Due to the impact of COVID-19 epidemic, many companies are facing financial crisis. The number of companies that run into difficulties or even go bankrupt due to financial risks has greatly increased. The financial crisis of company operation is usually caused by the accumulation of various problems in the company's long-term business activities, and these problems can be discovered and solved in advance. In general, companies can observe potential risks by regularly analyzing and observing financial statement data. In order to help companies to avoid and disperse financial risks in a timely and effective manner, the financial crisis warning system is particularly important in company's risk management. Many scholars have established financial crisis warning models for different industries, but the accuracy of the models still needs to be improved. So, this study adopts the method of data mining, using RPROP neural network and support vector machine (SVM), two years in 162 listed companies panel financial index data as the modeling sample, test sample, and a financial crisis warning model, in order to manage the financial risk of listed companies and guarantee smooth running of listed companies, securities market, and the national economy.

At present, most of the domestic relevant literatures use mathematical models to build financial crisis early warning systems or use various methods for comparison. This study also uses a comparative method and uses two neural network models to establish financial crisis early warning systems. These two neural network models include RPROP neural network and support vector machine. This result can provide a reference for the domestic financial sector and provide a basis for financial management for the investment public.

The structure of the following part of the article is as follows: the second part is the domestic and foreign financial crisis warning related literature, providing the background information of this part. In the third part, this paper will discuss two kinds of neural network models, including RPROP neural network and support vector machine, use these two methods to conduct financial crisis prediction analysis on two years' data of 162 listed companies, and use 
modeling and cross-validation to verify the accuracy of the models. In the last part, conclusions and suggestions will be made for the overall study.

\section{Literature Review}

Scholars at home and abroad have made many explorations on the construction of financial risk early warning system design model. Beaver [1] first used the traditional financial indicators to raise the rough judgment problem of a company's financial crisis and formally constructed a single-factor analysis model through statistical theory. However, the single-factor analysis model does not fully reflect the financial risk of a company. Therefore, the single-factor quantitative model has developed into a multifactor quantitative model. Edward Altman [2] proposed a multivariate linear multifactor model "Z-Score" to judge the severity of financial risks of companies by scoring results. However, because the Z-score model was not fully considered when establishing cash flow changes, it has a relatively large limitation. Therefore, Zhou [3] and other scholars transformed the Z-score model and established a new model for financial crisis prediction, the F-score model (Failure Score Model). With the establishment of the concept of information flow, Aziz et al. [4] proposed a model of forecasting financial distress with cash flow information in 1988. In 1993, Coats and Fant [5] built a financial early warning model based on the neural network theory. The model imitates the learning process of biological brain neural network without considering whether it conforms to the normal hypothesis, and can deal with nonquantifiable variables, which is widely applied. Also in 1999, univariate analysis and multivariate linear decision analysis were performed using financial statement data from 27 ST companies and 27 non-ST companies [6].

With the deepening of scientific research and the development of computer science and technology, other disciplines such as artificial intelligence and neural networks have also been applied to the theory of company's financial early warning systems. Continuously improving forecast accuracy has gradually become an important development direction in this field. Wilson and Sharda [7] used the method of artificial neural network to explore the prediction of company bankruptcy. Zhou and Wang [8] proposed a company financial crisis warning method based on system fuzzy optimization and neural network model and integrated the functions of company's financial crisis measurement, neural network dynamic learning and reasoning of financial crisis warning reasoning knowledge, and prediction of financial crisis indicators. From the perspective of cash flow, Liang [9] established the canonical rule judgment model and Fisher linear judgment model and made the prediction and the comparison of the results. Lin [10] took ST company and non-ST company with a ratio of $1: 2$ as the research object and constructed the Ologit financial crisis early warning model. Song [11] used relevant financial data of listed companies as a research sample and built a neural network model with deep learning as a research tool to predict whether a company would fall into financial crisis. The prediction accuracy could reach more than $72 \%$. Wu [12] took the listed companies on China's GEM as the research object and used Twin-SVM to construct the financial crisis early warning model for the nonequilibrium sample characteristics of the company's different financial conditions. Wang [13] presented a financial crisis early warning detection algorithm based on fuzzy cognitive map. In addition, some scholars have innovated to construct the financial risk warning model by fuzzy analytic hierarchy process [14], PCA-SVM [15], improved MRMR algorithm [16], and other methods. Although the research on financial early warning models in China has been deepened in recent years, it is still in the exploration stage, and there is still room for improvement in terms of prediction accuracy. Therefore, this study applies the $\mathrm{R}$ programming language, using RPROP neural network and support vector machine (SVM), with 162 listed companies panel two years' financial index data as the modeling sample, the test sample, and a financial crisis warning model, in order for managers of listed companies and other stakeholders to predict the company's financial situation to provide scientific decision means and reliable basis.

\section{Description of Research Methods and Indicators}

3.1. Resilient Back Propagation Neural Network (RPROPN). Back Propagation Network (BPN) is the most widely used artificial neural network. It is a multilayer feedforward network trained by error back propagation (referred to as error back propagation). Its algorithm is called BPN algorithm, and its basic idea is to use the gradient descent method search technology, in order to minimize the mean square error of the predicted output value and expected output value of the network. In the backward transfer phase, the link weights between nodes will be corrected in reverse according to the prediction error, which will make the predicted output of BPN network close to the target value after repeated corrections. However, the algorithm still has some shortcomings. The first is that its learning efficiency $\eta$ needs to be determined by us in advance; in addition, the weight change is based on the rate of change of the error gradient. Although at first glance this seems to be no problem, we dare not guarantee that it will always be correct and effective. To this end, Riedmiller et al. proposed the RPROP algorithm (resilient backpropagation) to improve the Backprop algorithm. In this study, we also adopted the improved BP algorithm, that is, the Resilient Back Propagation (RPROP), to construct a neural network prediction model.

3.2. Support Vector Machine(SVM). Support vector machine (SVM), proposed by Professor Vapnik (1995), is a supervised machine learning algorithm. The basic model is to find the optimal separation hyperplane in the feature space to maximize the positive and negative sample interval on the training set. The core idea is to separate the data by 
constructing a segmentation plane. It is most commonly used for categorical prediction problems.

3.3. Sample Collection and Index Selection. The data in this study uses data from companies listed on the Shanghai Stock Exchange and Shenzhen Stock Exchange. In a two-to-one way, 162 listed companies were selected, including 55 ST companies and 107 non-ST companies, and each group of three companies was in the same or similar industry in order to have better comparability. In this study, the panel data is formed with the data of each explanatory variable from 2015 to 2016. These sample companies are mostly in the real estate sector and the comprehensive sector. It should be noted that, for each ST company, we randomly select two non-ST companies in the same sector, and the overall number of samples is 1:2. In terms of scope, it should be objective. The sample composition of this study is shown in Table 1.

At present, there is a lack of more specific economic theory guidance for the selection of financial indicators, and the essential reasons for the company's special treatment are not necessarily the same. It is difficult to fully describe with simple financial ratio indicators. Therefore, we mainly take quantitative analysis and provide six indicators: turnover rate, total asset turnover rate, main business revenue growth rate, total asset growth rate, equity return rate, and asset return rate, which are based on the five financial strengths. And in order to better test the accuracy of the model, the 2015 and 2016 data of the indicators are selected for comparison, and the defined variables are shown in Table 2.

And according to the difference between 2015 and 2016, these explanatory variables $(\mathrm{X})$ data are based on the turnover rate (receivables turnover rate $(\mathrm{X} 1)$, total asset turnover rate (X2)), growth rate (main business revenue growth rate (X3), total asset growth rate (X4)), and return rate (return on equity (X5), return on assets (X6)) and other indicators are collected. The narrative statistics are shown in Table 3.

Among them, the crisis company (ST) included in the explanatory variable $(\mathrm{Y})$ refers to the company that has suffered losses for two consecutive years and is specially treated. It is represented by the value 1 and the normal company by the value 0 . In addition, in data processing, we divided all 162 pieces of data into 6 groups, and each group had 27 pieces of data. In the decision tree modeling, 5 groups of 135 data pieces were used to establish a decision tree model, and a group of 27 data pieces was substituted into the decision tree model to test the accuracy of the model for cross-validation. Therefore, there are 6 sets of data in the same year. In other words, the first group uses group 1-5 modeling and group 6 testing. The second group adopts group 2-6 modeling and group 1 testing. The third group adopts group 3-1 modeling and group 2 testing. The fourth group adopts group 4-2 modeling and the group 3 testing. The fifth adopts group 5-3 modeling and group 4 testing. The sixth group adopts group 6-4 modeling and group 5 testing. The same was done for two years, but the second year is marked with 7-12 groups. This method can help us to further analyze the accuracy of two kinds of neural network financial warning models.
TABLE 1: Sample statistics table.

\begin{tabular}{lccc}
\hline & ST & Non-ST & Total \\
\hline Total & 55 & 107 & 162 \\
\hline
\end{tabular}

TABLE 2: Variable definition.

\begin{tabular}{lc}
\hline Symbol & Meaning \\
\hline $\mathbf{Y}$ & Whether the company is special or not (ST $=1$, non- \\
$\mathrm{X}_{1 j}$ & ST $=0$ ) \\
$\mathrm{X}_{2 \mathrm{j}}$ & Turnover rate of company $\mathrm{j}$ in 2015 \\
$\mathrm{X}_{3 j}$ & Total asset turnover rate of company $\mathrm{j}$ in 2015 \\
$\mathrm{X}_{4 j}$ & Total asset growth rate of company $\mathrm{j}$ in 2015 \\
$\mathrm{X}_{5 j}$ & Equity return rate of company $\mathrm{j}$ in 2015 \\
$\mathrm{X}_{6 j}$ & Asset return rate of company $\mathrm{j}$ in 2015 \\
$\mathrm{X}_{7 j}$ & Turnover rate of company $\mathrm{j}$ in 2016 \\
$\mathrm{X}_{8 j}$ & Total asset turnover rate of company $\mathrm{j}$ in 2016 \\
$\mathrm{X}_{9 j}$ & Main business revenue growth rate of company $\mathrm{j}$ in 2016 \\
$\mathrm{X}_{10 j}$ & Total asset growth rate of company $\mathrm{j}$ in 2016 \\
$\mathrm{X}_{11 j}$ & Equity return rate of company $\mathrm{j}$ in 2016 \\
$\mathrm{X}_{12 \mathrm{j}}$ & Asset return rate of company $\mathrm{j}$ in 2016 \\
\hline
\end{tabular}

\section{Empirical Analysis}

4.1. Resilient Back Propagation Neural Network (RPROPN). In this study, the Resilient Back Propagation Neural Network is mainly implemented with the help of $R$ tool. For the purpose of comparative study, we confirmed the input nodes of the RPROP model by using the six same original financial indicators retained as the benchmark. The number of output nodes is 1 . If the network output result is less than the threshold value of the output layer, we would consider it to be an ST company. Otherwise, it is a non-ST company, and the threshold of the output layer is determined by the network training itself. The number of intermediate layers is set as 3 neurons, and the number of repetitions is 5 . A decision tree model is established based on a total of 12 sets of 135 data pieces in two years. The results are shown in Figures 1-12.

Through the established model, we, respectively, tested the 12 groups through 27 pieces of data in each group. Among them, we set the result as $Y=0$ below 0.5 and $Y=1$ above 0.5 , which is called correct judgment of the model. The test results are as follows.

4.2. Support Vector Machine (SVM). The support vector machine uses the Gaussian kernel function (RBF). The output of 0 represents financial normality and the output of 1 represents financial crisis. This experiment is based on the "linear space inseparable problem" and "nonlinear problem" to establish the SVM model. Under this model, two parameters need to be selected: "RBF kernel function density" and "penalty factor C." We know that gamma is a parameter that comes with the RBF function as the kernel. It implicitly determines the distribution of the data after mapping into a new feature space. The larger the gamma, the fewer the support vectors, and the smaller the gamma value, the more the support vectors. The number of support vectors affects 
Table 3: Descriptive statistics of each index.

\begin{tabular}{lcccccccccccc}
\hline Descriptive statistics & $\mathrm{X} 1$ & $\mathrm{X} 2$ & $\mathrm{X} 3$ & $\mathrm{X} 4$ & $\mathrm{X} 5$ & $\mathrm{X} 6$ & $\mathrm{X} 7$ & $\mathrm{X} 8$ & $\mathrm{X} 9$ & $\mathrm{X} 10$ & $\mathrm{X} 11$ & $\mathrm{X} 12$ \\
\hline Maximum & 7172.23 & 10.08 & 4335.66 & 924.57 & 1106.21 & 161.65 & 7172.23 & 10.08 & 4335.66 & 924.57 & 1106.21 & 161.65 \\
Minimum & 0.24 & 0.02 & -90.05 & -82.97 & -65.62 & -29.98 & 0.24 & 0.02 & -90.05 & -82.97 & -65.62 & -29.98 \\
Average & 91.11 & 0.65 & 46.31 & 23.44 & 135.51 & 16.14 & 91.11 & 0.65 & 46.31 & 23.44 & 135.51 & 16.14 \\
Standard deviation & 581.29 & 0.96 & 351.33 & 85.30 & 170.64 & 19.53 & 581.29 & 0.96 & 351.33 & 85.30 & 170.64 & 19.53 \\
\hline
\end{tabular}

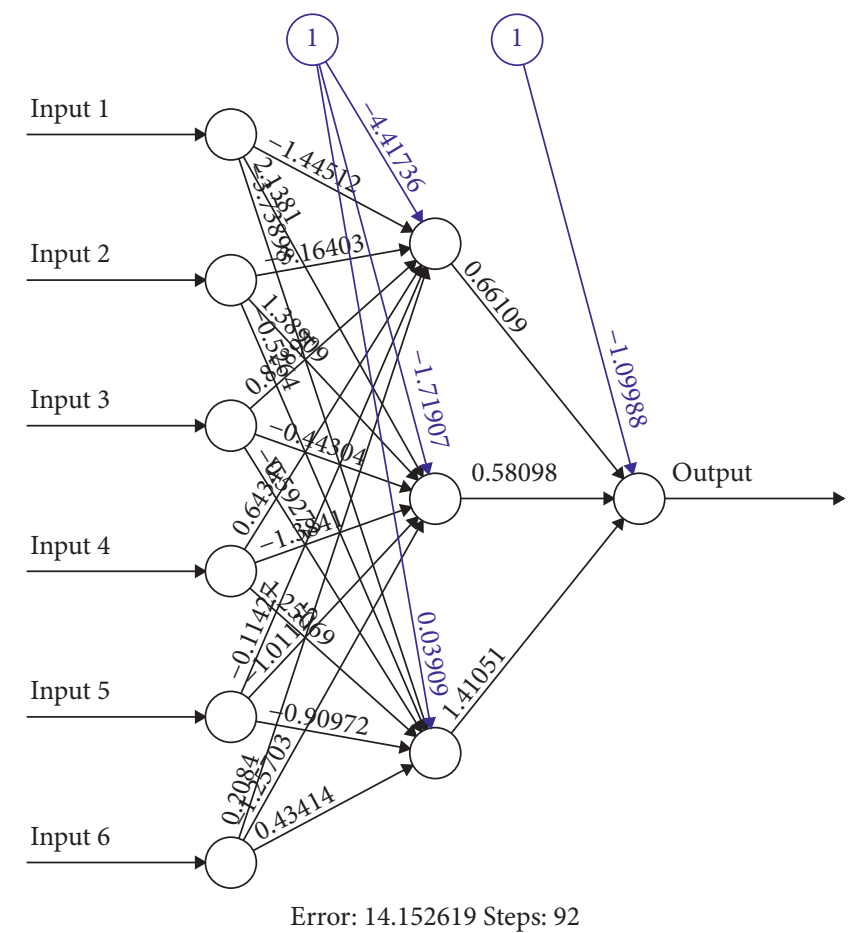

Figure 1: Group 1 modeling in 2015.

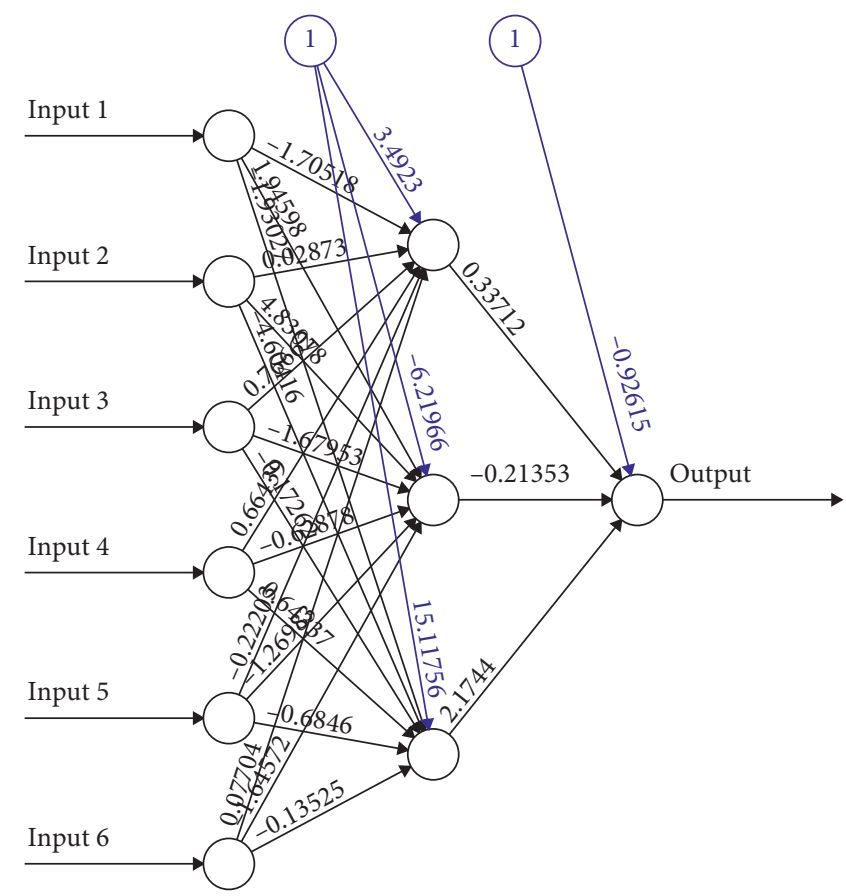

Error: 13.528471 Steps: 220

Figure 2: Group 2 modeling in 2015. 


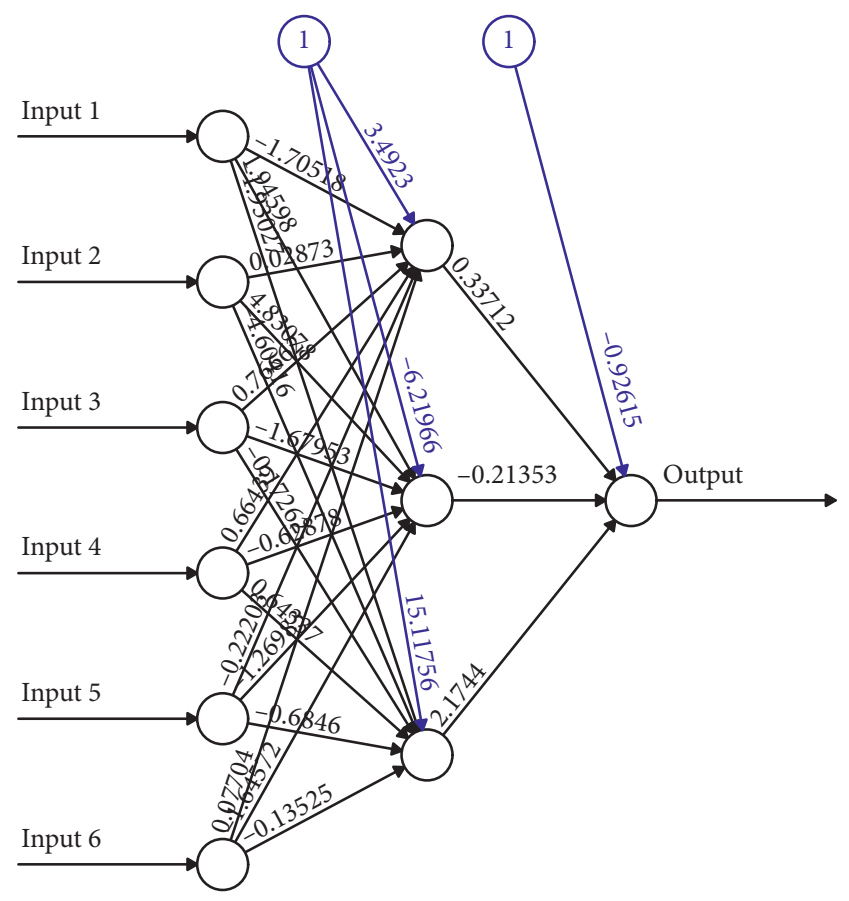

Error: 13.528471 Steps: 220

Figure 3: Group 3 modeling in 2015.

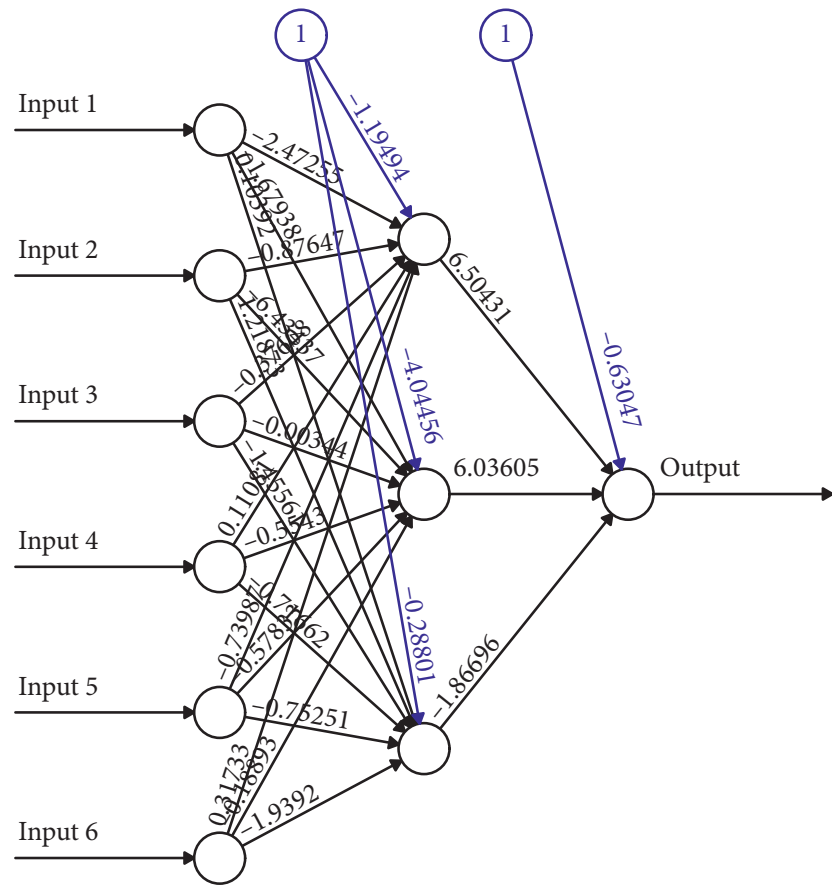

Error: 13.84064 Steps: 63

Figure 4: Group 4 modeling in 2015.

the speed of training and prediction. Through calculation research and case matching, here we set gamma $=0.01$, cost $=1$.

Finally, use the selected parameters and regularized data to train the SVM model, and the results are as follows.

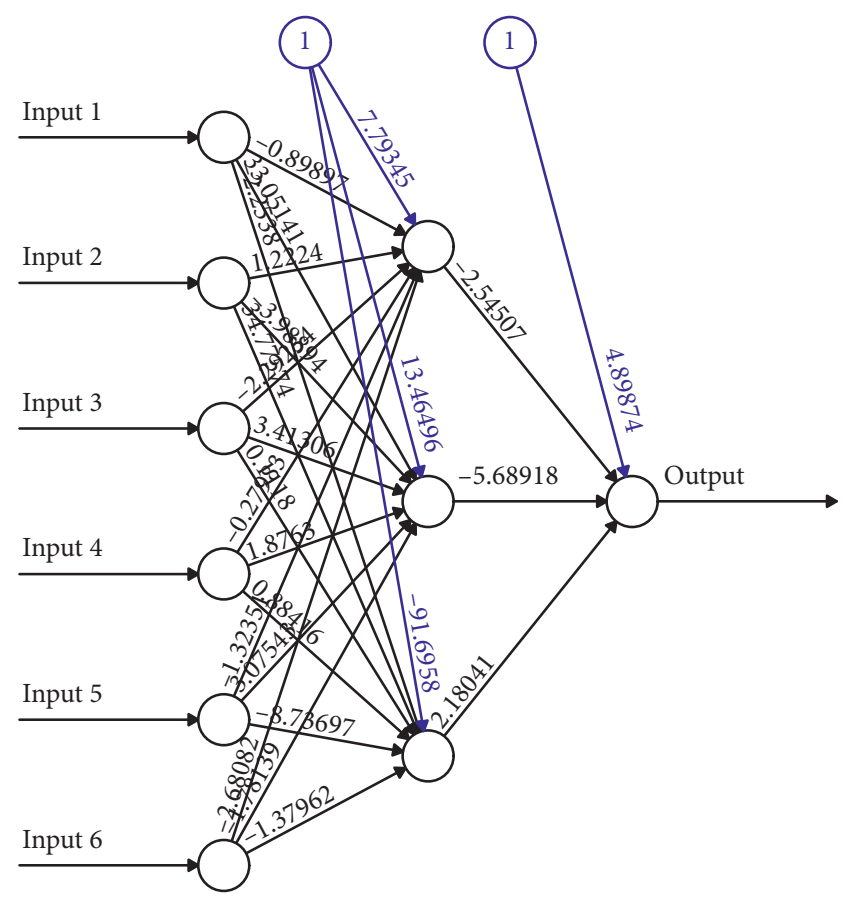

Error: 12.452405 Steps: 1827

Figure 5: Group 5 modeling in 2015.

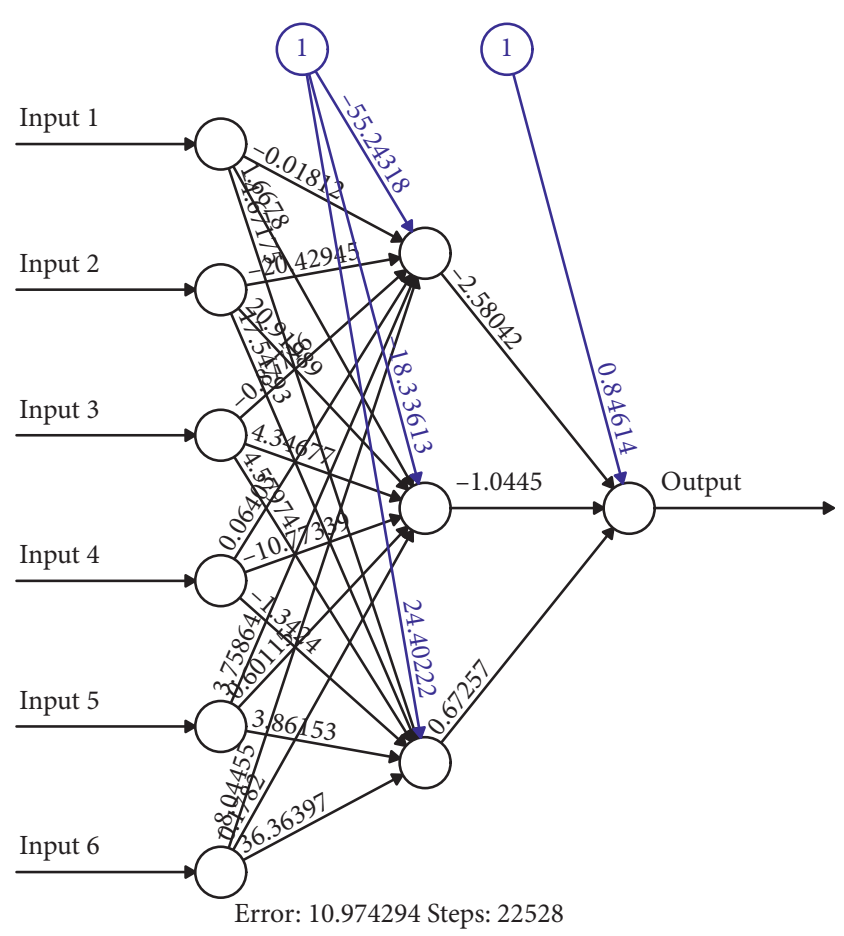

FIgURE 6: Group 6 modeling in 2015.

By comparing and analyzing the judgment results of Tables 4 and 5, the judgment results of applying RPROP artificial neural network model and support vector machine to predict the financial crisis of China's listed companies show the following. 


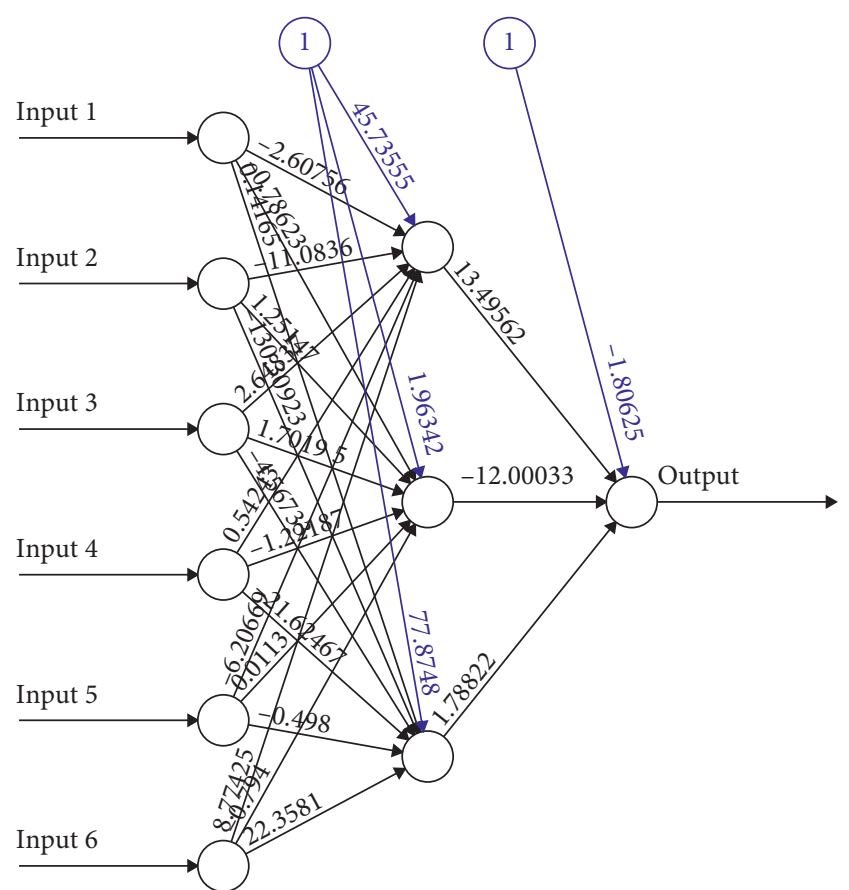

Error: 10.979337 Steps: 10674

Figure 7: Group 1 modeling in 2016.

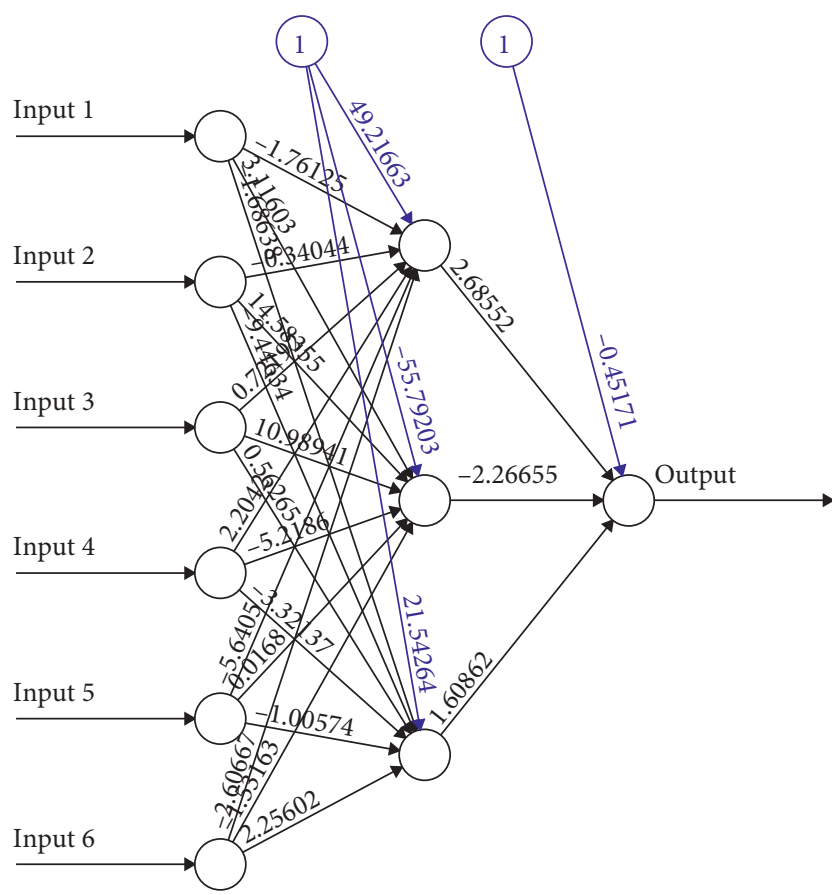

Error: 9.899326 Steps: 2033

FIGURE 8: Group 2 modeling in 2016.

First, the judgment accuracy of both models is acceptable, but in contrast, the judgment accuracy of the RPROP neural network model for ST companies is overall higher, indicating that the RPROP neural network model can fully learn the data information contained in the samples, which

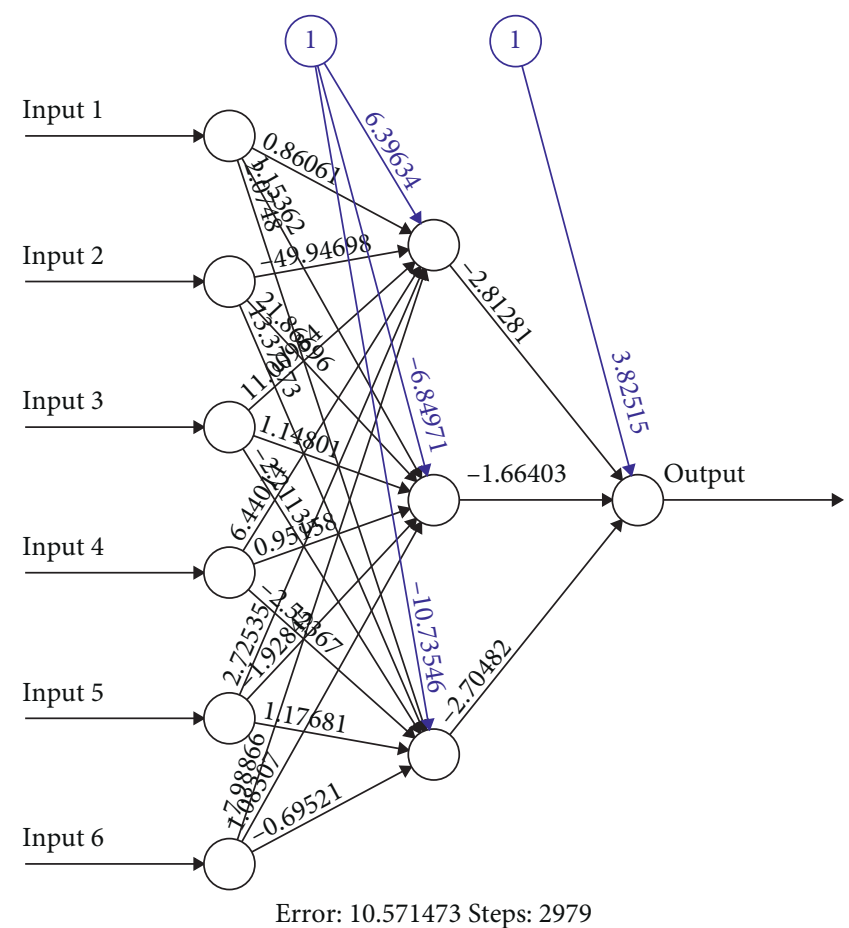

FIGURE 9: Group 3 modeling in 2016.

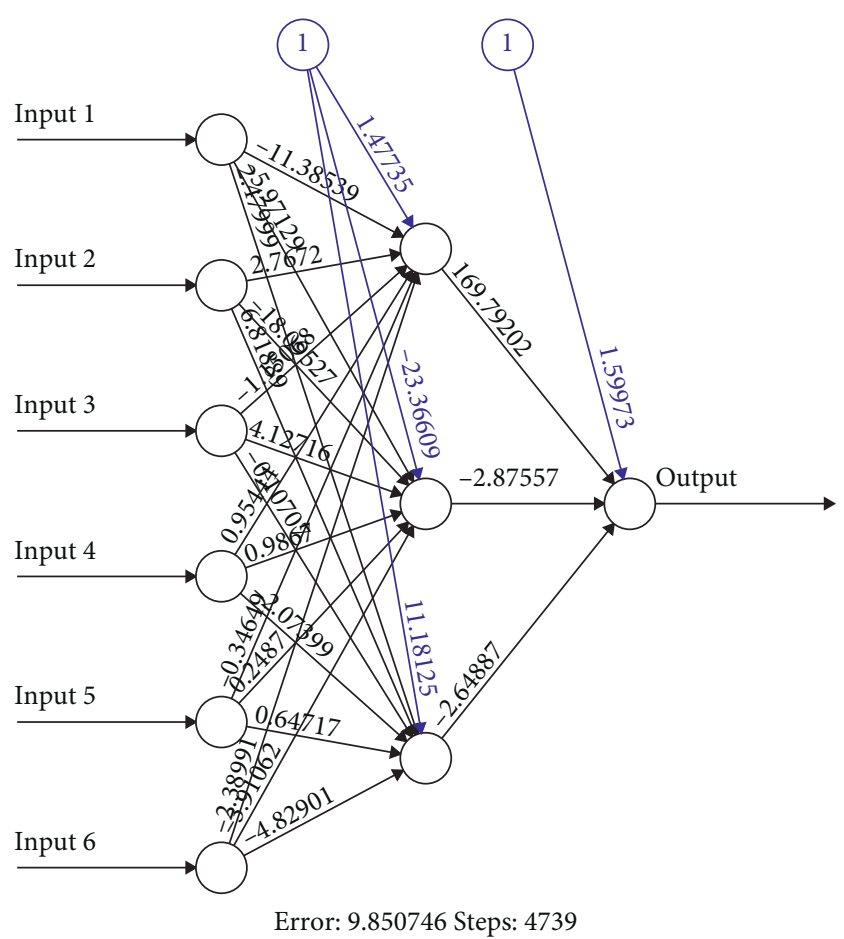

FIgUre 10: Group 4 modeling in 2016.

is conducive to improving the ability to judge the unidentified samples.

Second, the discriminant accuracy rate of the two models for ST companies is lower than that of non-ST companies, which is particularly obvious in the support vector machine 


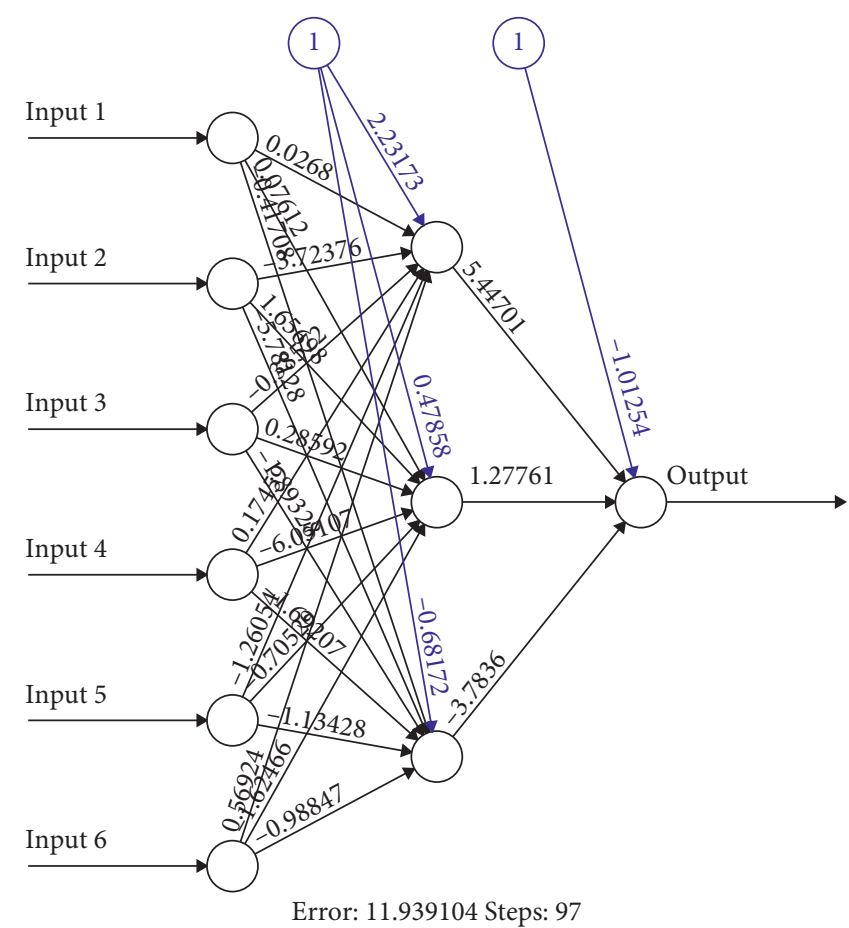

FIgURE 11: Group 5 modeling in 2016.

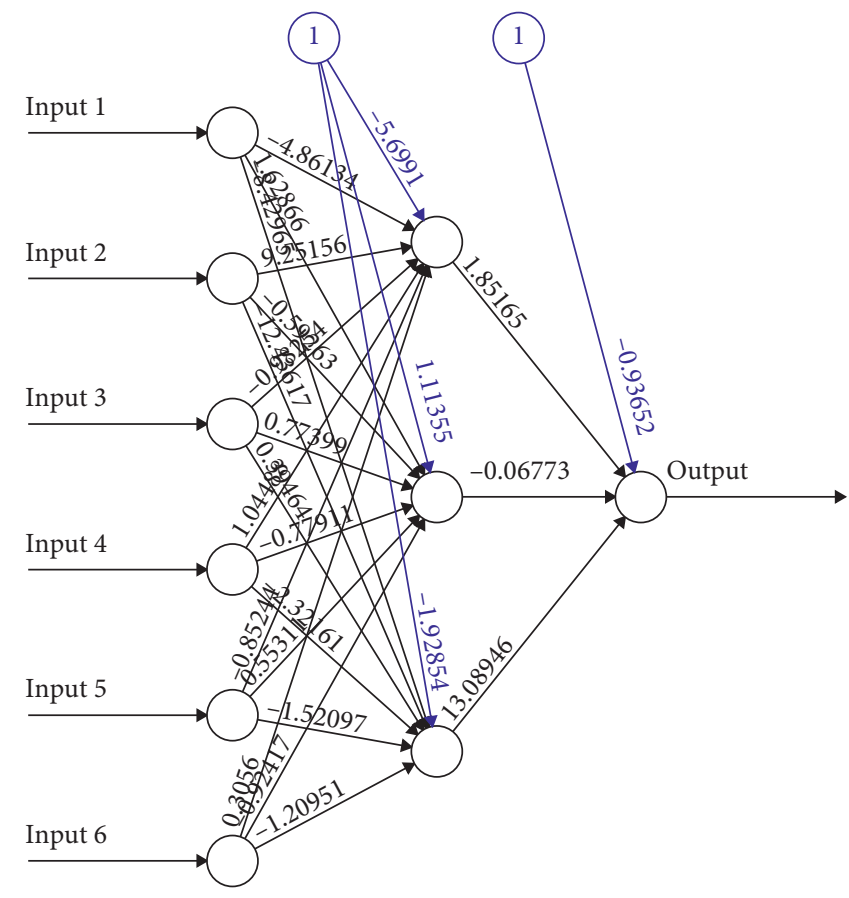

Error: 12.411807 Steps: 152

Figure 12: Group 6 modeling in 2016.

TABLE 4: RPROP's judgment on modeling samples.

\begin{tabular}{lcccc}
\hline & $\begin{array}{c}\text { Actual } \\
\text { number }\end{array}$ & $\begin{array}{c}\text { The average of the correctly judged } \\
\text { number }\end{array}$ & $\begin{array}{c}\text { Actual } \\
\text { number }\end{array}$ & $\begin{array}{c}\text { The average of the correctly judged } \\
\text { number }\end{array}$ \\
\hline ST & 9 & 0.17 & 9 & 3.83 \\
$\begin{array}{l}\text { Non-ST } \\
\text { Total number of }\end{array}$ & 18 & 16.83 & 18 & 15.33 \\
$\begin{array}{l}\text { companies } \\
\text { Accurate judgment rate }\end{array}$ & 28 & 19.17 & 28 & 20.17 \\
\hline
\end{tabular}


TABLE 5: SVM's judgment on test data.

\begin{tabular}{lcccc}
\hline & $\begin{array}{c}\text { Actual } \\
\text { number }\end{array}$ & $\begin{array}{c}\text { The average of the correctly judged } \\
\text { number }\end{array}$ & $\begin{array}{c}\text { Actual } \\
\text { number }\end{array}$ & $\begin{array}{c}\text { The average of the correctly judged } \\
\text { number }\end{array}$ \\
\hline $\begin{array}{l}\text { ST } \\
\text { Non-ST }\end{array}$ & 9 & 0.67 & 9 & 1.0 \\
$\begin{array}{l}\text { Total number of } \\
\text { companies }\end{array}$ & 18 & 18 & 18 & 18 \\
Accurate judgment rate & 28 & 18.67 & 28 & 19 \\
\hline
\end{tabular}

model. Through the analysis of a single sample of misjudgment, it can be found that the wrong samples are in a critical state of the ST and the ST listed company. But compared with the BP artificial neural network model, support vector machine (SVM) model for ST's discriminant accuracy is higher than the BP artificial neural network model. This is a conclusion worthy of in-depth discussion.

\section{Conclusions}

This study compares RPROP neural network and support vector machine algorithm to analyze the financial crisis of listed companies. The research results show that the RPROP artificial neural network method based on financial indicator information combined with support vector machine is a more effective method to predict whether financial crisis will occur in a company's finance. First, RPROP artificial neural network is used for the first round of troubleshooting, and then support vector machine is used for verification, which will make the whole result more reliable.

The research results show that the occurrence of financial crisis can be predicted in advance, and the experimental results show that the occurrence of financial crisis is the result of multiple factors. Using the $\mathrm{R}$ programming language, with the help of computer tools, the algorithm design and data calculation of the RPROP network model can be easily completed, and an early warning model of the financial crisis of listed companies can be established to provide a scientific basis for investors, creditors, and other stakeholders to predict the financial situation of the company, as well as to provide a reference basis for listed companies to strengthen their internal management and get rid of the financial crisis in a timely manner. It is suggested that listed companies can combine nonfinancial quantitative indicators to deeply explore financial statement information of listed companies and give early warning to companies with financial risks. The predicted results can enable the managers of listed companies to timely adjust their strategies, change their business model, and reduce or avoid losses. Investors have insight into the development prospects of listed companies and make rational investment. Creditors can avoid loan risks. In addition, it also provides a basis for the securities regulatory authorities to strengthen supervision over the listed companies with risks, which is of great economic and social significance to ensure the smooth operation of the listed companies, the securities market, and the national economy. Compared with other methods, the reason why the prediction accuracy is improved is that the
RPROP neural network model is a nonlinear separable mapping, and the data requirements for model variables are not particularly demanding. The lack of individual data has little effect on the prediction results of the model. The RPROP neural network learns more fully and contains more information on the original data. Therefore, we believe that the RPROP neural network model has broad application prospects and application value in analyzing and studying the financial situation of China's listed companies.

However, it should be noted that, first, in the research process, we have placed too much emphasis on the elements of the financial five-force model, and nonfinancial indicators and some nonquantitative indicators should also remain crucial in listed companies facing an increasingly fierce market. These are not noticed or ignored in our research and can be referenced in future research. Second, this study is conducted in two perspectives: cross-section and longitudinal tracking. This study only uses the cross-section financial data of the first two years of the listed company to establish a prediction model and then uses the listed companies in the overall sample of the same period to make a judgment test, indicating that the prediction model is effective for the prediction of the first two years of financial crisis. If a longer time chain is considered, whether the same principle or even the same model can be used for prediction requires a continuous follow-up investigation and research on the longitudinal data samples of the same company.

\section{Data Availability}

The original report data of all enterprise index data were obtained from the public data of listed companies on the official websites of Shanghai Stock Exchange and Shenzhen Stock Exchange. The data include indicators such as accounts receivable turnover rate, total asset turnover rate, main business income growth rate, total asset growth rate and return on equity, return on assets, and other indicators. All enterprise index data used to support the findings of this study are available from the corresponding author upon request.

\section{Conflicts of Interest}

The authors declare that they have no conflicts of interest.

\section{Acknowledgments}

This study was funded by a Key Research Project of Universities in Guangdong Province (2018WTSCX034). 


\section{References}

[1] W. H. Beaver, "Financial ratios as predictors of failure," Journal of Accounting Research, vol. 4, pp. 71-111, 1966.

[2] E. I. Altman, "Financial ratios, discriminant analysis and the prediction of corporate bankruptcy," The Journal of Finance, vol. 23, no. 4, pp. 589-609, 1968.

[3] S. Zhou, J. Yang, and P. Wang, "On the early warning analysis of financial crisis--F score model," Accounting Research, vol. 8, p. 4, 1996.

[4] A. Aziz, D. C. Emanuel, and G. H. Lawson, "Bankruptcy prediction-an investigation of cash flow based models," Journal of Management Studies, vol. 25, no. 5, pp. 419-437, 1988.

[5] P. K. Coats and L. F. Fant, "Recognizing financial distress patterns using a neural network tool," Financial Management, vol. 22, no. 3, pp. 142-155, 1993.

[6] J. Chen, "Empirical analysis of financial deterioration forecast of listed companies," Accounting Research, vol. 4, pp. 31-36, 1999.

[7] M. D. Odom and R. Sharda, "A neural network model for bankruptcy prediction," in Proceedings of the 1990 IJCNN International Joint Conference on Neural Networks, pp. 163168, IEEE, San Diego, CA, USA, June 1990.

[8] M. Zhou and X. Wang, "Enterprise financial crisis early warning based on fuzzy optimization and neural network," Journal of Management Science, vol. 3, pp. 86-90, 2002.

[9] F. Liang, "Empirical research on early warning system of financial crisis based on cash flow-a case study of machinery and equipment industry," Finance and Trade Economics, vol. 2, pp. 23-27, 2005.

[10] Q. Lin, "Research on early warning of financial crisis of listed companies based on Ologit model," Management, vol. 12, pp. 95-97, 2018.

[11] Ge Song, "Research on early warning model of financial risk for listed companies based on deep learning," Value Engineering, vol. 1, pp. 53-56, 2019.

[12] Q. Wu, "Identification and early warning of financial crisis of listed companies on GEM," Finance and Accounting Monthly, vol. 2, no. 0056, pp. 56-64, 2020.

[13] Q. Wang, F. Hui, X. Wang et al., "Research on early warning and monitoring algorithm of financial crisis based on fuzzy cognitive map," Cluster Computing, vol. 22, no. 2, pp. 1-9, 2019.

[14] S. Gao, "Application research on financial risk early warning of small and medium-sized enterprises under fuzzy analytic hierarchy process," China Business, vol. 11, pp. 46-47, 2020.

[15] X. Shi, "Construction of early-warning model of corporate financial crisis based on PCA-SVM," Journal of Finance and Accounting, vol. 10, pp. 131-134, 2020.

[16] K. Luo and G. Wang, "Research on financial early warning based on improved MRMR algorithm and cost sensitive classification," Statistics and Information Forum, vol. 35, no. 03, pp. 77-85, 2020. 